\title{
BEBERAPA SIFAT FISIKA DAN KIMIA TANAH PADA AREAL REVEGETASI TANAMAN SENGON DI WASTE DUMP TAMBANG BATUBARA DI KALIMANTAN SELATAN
}

\section{(SOIL PHYSICAL AND CHEMICAL PROPERTIES STUDY IN REVEGETATION AREA OF SENGON IN WASTE DUMP SOUTH KALIMANTAN)}

\author{
Dwi Ayu Fitrianti ${ }^{1)}$, Mohammad Nurcholis ${ }^{2) *}$, dan Djoko Mulyanto ${ }^{3)}$ \\ 1) Prodi Agroteknologi, Universitas Pembangunan Nasional Veteran Yogyakarta \\ ${ }^{2)}$ Prodi Ilmu Tanah, Universitas Pembangunan Nasional Veteran Yogyakarta \\ ${ }^{*}$ Corresponding author E-mail: nurcholis@ upnyk.ac.id
}

\begin{abstract}
Mining with open pit mining technique may decrease soil productivity because of the changes ini soil's physical, chemical, and biological characteristics like compaction, prone to soil, decrease in soil productivity, infiltration rate that of ground water recharge, decrease in soil $\mathrm{pH}$, decrease in microbial population. This research aimed to investigate factors that determine 5-the growth as 5-year old sengon trees as affected by physical and chemical properties. This research was conducted in the area of waste dump of a coal mine in Kalimantan Selatan using a survey method. Soil samples were taken using a purposive method by dividing the areas into 4 locations: flat 1, slopping 1, flat 2 and slopping 2; and the number samples taken were 12 in total. Collected data from each block were anlyzed their avarage and standard deviation. A regression test was used to acknowledge the relation among parameters, and a ' $t$ test' was to show the significant differences between areas. The results of the research showed that physical and chemical characteristics, and the growth of sengon tree on slopping locations than flat locations, and the determinant factors of the growth of sengon as the main vegetation were soil physical characteristic including porosity, permeability and clay content, and aslo soil chemical characteristic including soil organic-C, total of $\mathrm{N}$, available $\mathrm{P}$, and CEC.
\end{abstract}

Keywords: coal, physical characteristic, chemical characteristic, revegetation, sengon

\begin{abstract}
ABSTRAK
Pertambangan tambang terbuka dapat berakibat menurunkan produktivitas tanah karena perubahan sifat fisik, sifat kimiawi, dan sifat biologi tanah. Perubahan tersebut meliputi: pemampatan, penurunan daya tahan tanah terhadap erosi, penurunan produktivitas tanah, laju infiltrasi yang mempengaruhi air tanah, penurunan $\mathrm{pH}$ tanah, dan penurunan populasi mikroba tanah. Penelitian ini bertujuan untuk mengetahui faktor penentu pertumbuhan tanaman sengon berhubungan dengan sifat fisika dan kimia tanah sehingga dapat menyebabkan terjadinya perbedaan pertumbuhan pada tanaman sengon berumur 5 tahun. Penelitian dilakukan di areal waste dump tambang batubara di Kalimantan Selatan, dengan menggunakan metode survei. Pengambilan sampel tanah dilakukan dengan metode purposif dengan membagi areal menjadi 4 lokasi yaitu datar 1, miring 1, datar 2 dan miring 2 dan sampel yang diambil berjumlah 12 buah. Data hasil setiap blok dihitung rata-rata dan deviasi standarnya. Unuk mengetahui hubungan antar parameter digunakan analisis regresi, dan untuk mengetahui perbedaan yang signifikan antar area digunakan Uji t. Hasil penelitian menunjukkan bahwa sifat fisik, kimiawi dan
\end{abstract}


pertumbuhan sengon pada kemiringan lebih baik dari pada areal datar dan faktor penentu pertumbuhan sengon sebagai vegetasi utama untuk sifat fisik adalah porositas, permeabilitas dan tinggi lempung, sedangkan untuk sifat kimia adalah C-organik, total N, P tersedia, dan KPK.

Kata kunci : batubara, sifat fisika, sifat kimia, revegetasi, sengon

\section{PENDAHULUAN}

Sistem pertambangan dengan teknik terbuka mengubah bentang lahan serta degadrasi lahan, yang selama ini telah menjadi isu nasional. Penurunan produktivitas tanah akibat berubahnya sifat fisik, sifat kimia dan sifat biologi tanah seperti terjadinya pemadatan, berkurangnya daya tanah terhadap erosi dan sedimentasi, penurunan laju infiltrasi yang akan mempengaruhi proses pengisian (recharge) air tanah, penurunan $\mathrm{pH}$ tanah, serta menurunnya populasi mikroba. Menurut hasil penelitian Munawar (1999) bahwa tanah lapisan atas lahan bekas pertambangan terbuka sangat heterogen dan memiliki berat isi tinggi, total pori rendah, kandungan $\mathrm{N}$ dan $\mathrm{P}$ rendah, cadangan $\mathrm{Ca}$ dan Mg tinggi dan populasi mikroba tanah rendah dibandingkan dengan tanah hutan di sekitarnya. Munculnya berbagai dampak negatif tersebut disebabkan antara lain karena proses pengupasan tanah dan pengelolaan top soil yang buruk, ditandai dengan tercampurnya lapisan top soil dengan sub soil atau bahkan overburden. Tanah bagian atas tergantikan tanah lapisan bawah yang kurang subur. Demikian juga populasi mikroorganisme yang ada di tanah lapisan atas menurun atau tidak berfungsi sebagaimana mestinya. Tanaman sengon dipilih sebagai tanaman pioner sebab memiliki beberapa kelebihan di antaranya mampu hidup toleran pada tanah pasir maupun salin. Di samping itu tanaman sengon buto merupakan jenis pohon yang cepat tumbuh, memiliki tajuk yang lebar sehingga mampu mengurangi adanya erosi oleh air hujan serta mampu melakukan fiksasi $\mathrm{N}$ bebas di udara. Oleh sebab itu, penelitian ini bertujuan untuk mengetahui yang menjadi faktor penentu pertumbuhan tanaman sengon berhubungan dengan sifat fisika dan kimia tanah sehingga dapat menyebabkan terjadinya perbedaan pertumbuhan pada tanaman sengon berumur 5 tahun.

\section{BAHAN DAN METODE}

Penelitian dilaksanakan di areal reklamasi khususnya areal revegetasi lahan pasca tambang pada Waste Dump Tambang Batubara Kalimantan Selatan. Metode penelitian menggunakan metode survey sedangkan pengambilan sampel menggunakan metode purposif sampling dengan membagi menjadi 4 lokasi diantaranya datar 1, miring 1 , datar 2 dan miring 2 berdasarkan perbedaan kemiringan lereng. Dimana masing-masing lokasi diambil 3 titik sampel. Selanjutnya dilakukan pengamatan pertumbuhan tanaman sengon serta dilakukan pengukuran tinggi tanaman, diameter batang dan lebar tajuk tanaman. 


\section{HASIL DAN PEMBAHASAN}

\section{Sifat Fisika Tanah}

Pada penelitian ini dilakukan analisis sifat fisika tanah meliputi parameter berat volume, berat jenis, porositas, permeabilitas, kadar lempung dan tekstur. Berdasarkan keseluruhan hasil dari sifat fisika tanah di Waste Dump (Tabel 1) memiliki karakteristik berupa nilai BV dengan rentan $1,19-1,29 \mathrm{~g} / \mathrm{cm}^{3}$, nilai BJ berkisar 2,20-2,32 $\mathrm{g} / \mathrm{cm}^{3}$, porositas berkisar 43,47 - 45,55\% .

Tabel 1. Sifat fisika tanah yang diteliti

\begin{tabular}{lcccccc}
\hline \multirow{2}{*}{ Blok } & \multicolumn{6}{c}{ Sifat fisika tanah } \\
\cline { 2 - 7 } & $\begin{array}{c}\mathbf{B V} \\
\left(\mathbf{g} / \mathbf{c m}^{\mathbf{3}}\right)\end{array}$ & $\begin{array}{c}\mathbf{B J} \\
\left(\mathbf{g} / \mathbf{c m}^{\mathbf{3}}\right)\end{array}$ & $\begin{array}{c}\text { Por } \\
(\mathbf{\%})\end{array}$ & $\begin{array}{c}\text { Per } \\
(\mathbf{c m} / \mathbf{j a m})\end{array}$ & $\begin{array}{c}\text { Lempung } \\
(\mathbf{\%})\end{array}$ & Tekstur \\
\hline Datar 1 & 1,29 & 2,32 & 44,36 & 5,86 & 27,77 & sandy clay loam \\
Miring 1 & 1,22 & 2,24 & 45,53 & 5,66 & 27,32 & sandy clay loam \\
Datar 2 & 1,28 & 2,28 & 43,47 & 5,55 & 49,13 & clay \\
Miring 2 & 1,19 & 2,20 & 45,55 & 5,72 & 52,80 & clay \\
\hline
\end{tabular}

Keterangan: BV = Berat Volume; BJ = Berat Jenis; Por $=$ Porositas; Per $=$ Peremeabilitas

Permeabilitas berkisar 5,55-5,72 cm/jam. Hasil ini memiliki harkat sedang sampai lambat. Kadar lempung 27,32 hingga 52,80 \% yang menyebabkan perubahan kelas tekstur dari sandy clay loam menjadi clay. Meningkatnya nilai BV, BJ serta menurunnya porositas pada blok datar diduga akibat daerah datar lebih padat dibandingkan daerah miring atau lereng disebabkan karena kegiatan grading oleh alat berat dalam proses penataan lahan. Hal ini dapat menyebabkan terjadinya pemdatan tanah disebabkan pori-pori tanah yang tertutup. Disamping itu, rendahnya porositas tanah pada metode reklamasi disebabkan rendahnya penutup tanah, tajuk dan perakaran pohon, produksi seresah serta aktivitas organisme tanah (Patiung et al., 2011). Ukuran pori dan pemadatan tanah berpengaruh terhadap peningkatan nilai porositas sehingga berdampak pada peningkatan aerasi dan kandungan air tanah. Permeabilitas tanah meningkat disebabkan oleh adanya keterkaitan dengan sifat fisik tanah seperti porositas dan bobot isi. Peningkatan pori makro tanah mampu meningkatkan permeabilitas tanah dan sebaliknya semakin sedikit pori tanah menurunkan permeabilitas. Peningkatan nilai rata-rata kadar lempung diduga akibat ukuran diameter lempung yang sangat kecil $<0,002 \mathrm{~mm}$ menyebabkan partikel lempung akan mudah terdispersi oleh air hujan. Semakin halus tekstur tanah semakin tinggi kemampuannya dalam menahan air yang tersedia untuk pertumbuhan tanaman. Namun kondisi aerasi tanah menjadi jelek dan sifat pengolahan tanahnya semakin berat.

\section{Sifat Kimia Tanah}

Pada penelitian ini dilakukan analisis sifat kimia tanah meliputi parameter COrganik, $\mathrm{N}$ total, $\mathrm{P}$ tersedia, $\mathrm{pH} \mathrm{H}_{2} \mathrm{O}, \mathrm{pH} \mathrm{KCl}, \mathrm{pH} \mathrm{H}_{2} \mathrm{O}_{2}$, KPK dan Kejenuhan basa atau KB (Tabel 2). Dari keseluruhan hasil sifat kimia pada Waste memiliki pola yang beragam dengan kandungan $\mathrm{C}$-Organik berkisar dari rendah hingga sedang dari $1,24 \%$ hingga $2,33 \%$. Kadar $\mathrm{N}$ total tanah keseluruhan blok memiliki hasil rendah berkisar anatar 0,13\% hingga 0,39\%. Sedangkan untuk kadar P tersedia 
sangat beragam dari harkat sangat rendah yakni 1,4 ppm hingga tinggi $22 \mathrm{ppm}$. Keseluruhan blok memiliki $\mathrm{pH}$ aktual netral berkisar antara 7,1 hingga 7,3, sedangkan $\mathrm{pH} \mathrm{KCl}$ berkisar antara 3,8- 5. Untuk $\mathrm{pH}_{2} \mathrm{O}_{2}$ berkisar antara 3-3,7. KPK tanah berkisar anatara 7,3 hingga 9,9 me/100g dengan harkat rendah sedangkan kejenuhan basa dengan harkat sangat tinggi.

Kandungan C-Organik yang rendah ini wajar karena pada saat penambangan batubara, terjadi pengupasan lapisan atas yang umunya mengandung bahan organik dan penempatanya setelah digali umumya bercampur. Sehingga pada saat backfilling sering kali lapisan tanah atas tidak ditempatkan di bagian atas dan bahan organiknya sudah bercampur. Rendahnya kandungan C-Organik tanah pada lahan reklamasi karena top soil yag digunakan dalam penataan lahan (regrading) reklamasi diduga

Tabel 2. Beberapa sifat kimia tanah

\begin{tabular}{lccccccc}
\hline \multirow{2}{*}{ Blok } & \multicolumn{7}{c}{ Sifat Kimia } \\
\cline { 2 - 8 } & $\begin{array}{c}\text { C-organik } \\
(\mathbf{\%})\end{array}$ & $\begin{array}{c}\text { N-total } \\
(\boldsymbol{\%})\end{array}$ & $\begin{array}{c}\text { P tersedia } \\
(\mathbf{p p m})\end{array}$ & $\begin{array}{c}\mathbf{p H} \\
\mathbf{H}_{\mathbf{2}} \mathbf{O}\end{array}$ & $\begin{array}{c}\mathbf{~ K H} \\
\mathbf{K C l}\end{array}$ & $\begin{array}{c}\text { KPK } \\
\mathbf{c m o l}(+/) \mathbf{k g}\end{array}$ & $\begin{array}{c}\text { KB } \\
(\boldsymbol{\%})\end{array}$ \\
\hline Datar 1 & 1,74 & 0,13 & 4,5 & 7,1 & 3,8 & 7,3 & 80,6 \\
Miring 1 & 2,33 & 0,17 & 1,4 & 7,1 & 4,9 & 8,9 & 73,4 \\
Datar 2 & 2,31 & 0,28 & 22,0 & 7,2 & 5,0 & 9,9 & 91,8 \\
Miring 2 & 1,24 & 0,39 & 1,9 & 7,3 & 4,3 & 6,9 & 85,8 \\
\hline
\end{tabular}

telah tercampur dengan subsoil.Peningkatan bahan organik dapat disebabkan oleh hasil pelapukan seresah tanaman revegetasi dari tahun ke tahun semakin besar. Seresah bagian batang, ranting dan daun tanaman yang jatuh berperan dalam meningkatkan kandungan bahan organik tanah (Arsyad, 2006).

Tanaman legum selama pertumbuhannya mampu menimbun Nitrogen terikat hasil pengikatan $\mathrm{N}$ bebas secara simbiotik dengan melibatkan jasad renik tertentu. Penanaman jenis-jenis cepat tumbuh yang mempunyai daun banyak dapat menambat nitrogen dari udara sebagai salah satu cara pengembalian unsur $\mathrm{N}$ pada tambang (Sutedjo dan Kartasapoetra, 1991). Istomo (2006) menyatakan bahwa P dalam tanah dominan berasal pelapukan batuan. Diduga $\mathrm{P}$ rendah pada lahan pasca revegetasi tidak dapat tersedia akibat terikat oleh logam ada dalam tanah sehingga tidak mampu tersedia bagi tanaman.

Keseluruhan blok memiliki $\mathrm{pH}$ yang netral. Hal ini menandakan bahwa penataan lahan serta penyimpanan top soil selama di stok top soil pada lokasi penelitian cukup bagus ditunjukkan dengan netralnya $\mathrm{pH}$ tanah. Sedangkan untuk $\mathrm{pH} \mathrm{KCl}$ Masing-masing blok dapat menjadi asam pada $\mathrm{pH}$ yang berbeda. Hal ini diduga selain dipengaruhi oleh perbedaan sumber top soil yang disebar juga akibat teroksidasinya pirit sehingga dapat membentuk garam dan asam sulfat menyebabkan $\mathrm{pH}$ tanah tersebut berpotensi menjadi asam.

Nilai KPK tanah bervariasi menurut tipe dan jumlah koloid dalam tanah. KPK tanah juga dipengaruhi oleh sifat dan ciri tanah tersebut yaitu $\mathrm{pH}$ tanah, tekstur atau jumlah liat, jenis mineral liat, bahan organikdan pengapuran/pemupukan (Hakim et $a l$, 1986). Makin tinggi nilai KPK maka unsur-unsur dalam tanah makin mudah untuk dipertukarkan dalam koloid tanah mudah tersedia bagi tanaman. Dapat dilihat dimana blok dengan bentuk datar memiliki kadar kejenuhan basa lebih tinggi 
dibanding blok miring. Hal ini diduga akibat adanya pencucian oleh air hujan yang menyebabkan basa-basa tertukar mudah larut dan mengendap pada blok yang memiliki bentuk datar.

\section{Keragaman Tanaman Sengon}

Pada lahan-lahan reklamasi, tanaman berumur sama pada daerah sisi lereng umumnya memiliki pertumbuhan yang lebih baik dibandingkan tanaman pada daerah datar sebab pada daerah datar biasanya lebih padat dibanding daerah lereng sehingga perakaran tanaman lebih mampu berkembang pada daerah lereng (Tabel 3). Hal ini dapat terjadi diduga akar tanaman pada daerah miring lebih dapat berkembang serta mendapatkan unsur hara yang lebih dibanding akar tanaman yang hidup pada daerah datar ini disebabkan karena padatnya tanah pada bagian datar sehingga sulit ditembus oleh akar tanaman.

Tabel 3. Rata-rata tinggi tanaman dan lebar tajuk tanaman serta diameter batang tanaman sengon

\begin{tabular}{lccc}
\hline \multirow{2}{*}{ Blok } & \multicolumn{3}{c}{ Keragaan tanaman } \\
\cline { 2 - 4 } & $\begin{array}{c}\text { Tinggi tanaman } \\
(\mathbf{m})\end{array}$ & $\begin{array}{c}\text { Lebar tajuk } \\
(\mathbf{m})\end{array}$ & $\begin{array}{c}\text { Diameter batang } \\
(\mathbf{c m})\end{array}$ \\
\hline Datar 1 & 10,10 & 4,47 & 18,36 \\
Miring 1 & 10,80 & 6,18 & 17,41 \\
Datar 2 & 15,03 & 4,81 & 17,41 \\
Miring 2 & 13,80 & 5,87 & 21,33 \\
\hline
\end{tabular}

Sumber top soil yang berasal dari titik maupun lokasi mana saja akan bercampur dan menghasilkan sifat yang beragam. Dengan pemindahan top soil dari kondisi awal lalu disimpan di lokasi penyimpanan top soil yang cukup lama juga dapat menjadikan berubahnya sifat tanah dari aslinya. Selain itu, apabila masih terdapat top soil sisa dari pit sebelumnya maka top soil tersebut akan dimanfaatkan sebagai stok untuk kegiatan reklamasi berikutnya. Dari berbagai keadaan tersebut dapat dimungkinkan tanah saling bercampur meskipun tidak merubah kondisi awal tanah tersebut atau dalam artian masih sama seperti dengan material pembentuknya. Hal ini dapat mempengaruhi sifat fisika maupun kimia tanah tersebut ini dibuktikan dari hasil analisis dan perhitungan didapatkan hasil yang cukup beragam. Dari fakta ini lah yang menjadikan tanah tersebut memiliki sifat yang beragam.

\section{KESIMPULAN}

Berdasarkan hasil penelitian dapat disimpulkan bahwa perubahan sifat fisika dan kimia tanah antar blok tidak menunjukkan perbedaan yang signifikan setelah direvegetasi dengan tanaman sengon berumur 5 tahun. Parameter sifat fisika yang menjadi penentu pertumbuhan tanaman sengon adalah porositas, permeabilitas dan kadar lempung yang hubungannya dengan tekstur tanah. Sedangkan sifat kimia tanah adalah $\mathrm{C}$ Organik, $\mathrm{N}$ total $\mathrm{P}$ tersedia serta KPK. Dengan nilai CV yang beragam maka didapatkan hasil bahwa tanah tersebut memiliki sifat yang acak dan beragam serta tidak membentuk pola. 


\section{DAFTAR PUSTAKA}

Anderson, J.M. 1994. Functional Attributes of Biodiversity in Land Use System: In D. J. Greenland and I. Szabolcs (eds). Soil Resiliense and Sustainable Land Use.

CAB International. Oxon.

Arsyad, S. 2010. Konservasi Tanah dan Air. Bandung: IPB Press.

Hakim, N., Nyakpa M., Y., A. M. Lubis., S. G. Nugroho., M. R. Saul., G.B. Hong., H.H. Baely. 1986. Dasar-Dasar Ilmu Tanah. Lampung: Universitas Lampung.

Istomo. 2006. Evaluasi dan Penyesuaian Sistem Silvikultur Hutan Rawa Gambut, Khususnya Jenis Ramin di Indonesia. Prosiding Workshop Nasional Alternatif Kebijakan dalam Pelestarian dan Pemanfaatan Ramin. Bogor. Pusat Penelitian dan Pengembangan Hutan dan Konservasi Alam.

Munawar, 1999. Coal Mine Soil Reclamation and Itd Possible Agricultural Uses in Bengkulu. Pros. Sem. Toward Sustainble Agriculture in Humid Tropics Facing 21st Century 107-124.

Patiung, O., Naik. S., Suria D., T., dan Dudung D. 2011. Pengaruh Umur Reklamasi Lahan Bekas Tambang Batubara Terhadap Fungsi Hidrologis. Jurnal Hidrolian, Vol 2:2: 60-73.

Setyawan, D. dan H. Hanum, 2014. Respirasi Sebagai Indikator Kepulihan Lahan Pasca

Tambang Batubara di Sumatera Selatan: Fakultas Pertanian. Universitas Sumatera Utara

Sutedjo dan Kartasapoetra, 1991. Pengantar Ilmu Tanah. Jakarta: PT. Bina Aksara.

Tala'olu, S., H., S. Moersidi, Sukristiyonubowo dan S. Gunawan. 1995. Sifat Fisik dan Kimia Tanah Timbunan Tambang Batubata (PTBA) di Tanjung Enim, Sumatera Selatan. Prosiding Pertemuan Pembahasan dan Komunikasi Hasil Penelitian Tanah dan Agroklimat, Bidang Konservasi Tanah dan Air, Serta Agroklimat Pusat Penelitian Tanah dan Agroklimat. Cisarua 26-28 September 1995. Bogor. Hal 42-52. 